\title{
"A GENTE FALA MUITO ERRADO O PORTUGUÊS": REPRESENTAÇÕES SOBRE LÍNGUAS EM UM CONTEXTO PLURILÍNGUE
}

\author{
"WE SPEAK PORTUGUESE VERY WRONGLY": \\ REPRESENTATIONS ABOUT LANGUAGES IN A PLURILINGUAL \\ CONTEXT
}

\author{
Martha Regina Maas ${ }^{1}$, Maristela Pereira Fritzen ${ }^{2}$
}

\begin{abstract}
RESUMO: Este artigo tem por objetivo discutir representações sobre as línguas alemã e portuguesa que emergem dos enunciados de diferentes gerações de uma família residente no Sul do Brasil, que mantém o alemão como língua de herança. Os dados foram gerados por meio de entrevistas e fazem parte do corpus de uma pesquisa mais abrangente, de cunho interpretativista, vinculada às áreas de Educação e Linguística Aplicada. Os dados sugerem que as representações construídas pelos sujeitos não são estanques, mas estão relacionadas ao momento histórico no qual estão inseridos, às suas experiências vividas e aos discursos sobre as línguas e seus falantes produzidos socialmente e em torno de suas comunidades.
\end{abstract}

Palavras-chave: representações; língua alemã; língua portuguesa; contexto plurilíngue.

ABSTRACT: This article aims to discuss representations about the German and Portuguese languages that emerge from the statements produced by different generations of a family residing in Southern Brazil, which maintains German as a language of inheritance. The research data were generated by means of interviews and are part of the corpus of a interpretative research, linked to the areas of Education and Applied Linguistics. The data suggest that the representations constructed by the subjects are not tight, but are related to the historical moment, their lived experiences and the discourses on the languages and their socially produced speakers and around their communities.

Keywords: representations; German language; Portuguese language; plurilingual context.

\section{Considerações iniciais}

O Brasil é um país plurilíngue (ALTENHOFEN, 2013; MAHER, 2007), formado por uma diversidade que perpassa muitas origens e tradições: as comunidades indígenas, os imigrantes europeus, as populações que vivem nas fronteiras, bem como as diferentes

\footnotetext{
${ }^{1}$ Mestra em Educação pela Universidade Regional de Blumenau (FURB). Professora de língua inglesa.

${ }^{2}$ Doutora em Educação pela Universidade Estadual de Campinas (UNICAMP). Professora do Programa de PósGraduação em Educação e do Departamento de Letras (FURB).
} 
manifestações culturais que compõem esse país de dimensões continentais. Essa pluralidade linguística e cultural se soma ao processo de ascensão das línguas internacionais, aprendidas formalmente, na escola, carregadas de valor mercadológico nas sociedades contemporâneas. Assim, o contato/conflito (CALVACANTI, 2011; FRITZEN, 2011, 2012) entre as diversas línguas e suas modalidades também se apresenta de forma plural no território brasileiro.

Diante desse contexto, o presente artigo tem como objetivo discutir representações sobre as línguas alemã e portuguesa que emergem dos enunciados de diferentes gerações de uma mesma família que vive em contexto bi/plurilíngue no sul do país. Os dados para discussão são provenientes de uma pesquisa mais abrangente ${ }^{3}$, de cunho interpretativista (CAVALCANTI, 2006), na qual se buscou compreender as relações entre escolarização e língua de imigração nos enunciados de sujeitos provenientes de uma família que mantém o alemão como língua de herança familiar.

A fim de atender ao objetivo da pesquisa, foram realizadas entrevistas semiestruturadas com os sujeitos que residem em zona rural. Esses momentos aconteceram na residência dos sujeitos e somaram cinco horas de conversa nas quais eles puderam falar sobre o alemão, língua de imigração aprendida e praticada no ambiente familiar, bem como acerca da língua portuguesa e sua relação com o processo de escolarização de cada um dos sujeitos. Para o presente artigo, selecionamos apenas os excertos que diziam respeito ao tema aqui enfocado "representações sobre as línguas alemã e portuguesa". Assim, devido ao limitado espaço para aprofundamento e discussão, discutiremos os fragmentos que se inserem no foco deste artigo. Quanto à metodologia, após a realização das entrevistas, os dados foram transcritos a partir das convenções de Preti (1999) ${ }^{4}$.

A análise desses dados se deu a partir da perspectiva teórica da Análise Dialógica do Discurso (PAULA, 2013) em diálogo com os Estudos Culturais (HALL, 2006; SILVA, 1999) e a Linguística Aplicada (RAJAGOPALAN, 2013; CANAGARAJAH; 2013), especialmente com autores que pesquisam a escolarização em contextos de línguas minoritárias/ minoritarizadas (CAVALCANTI, 1999; 2011; MAHER, 2007; 2013). Para pesquisar esse

\footnotetext{
${ }^{3}$ Durante a realização da pesquisa, foram entrevistas três gerações de duas famílias. Para este artigo, fizemos um recorte dos registros de uma das famílias entrevistadas. A pesquisa foi aprovada, em oito de outubro de 2014, pelo Comitê de Ética da Universidade, junto à Plataforma Brasil.

${ }^{4}$ Para a transcrição de dados, as convenções utilizadas foram adaptadas a partir de Preti (1999):

Entonação enfática - MAIÚSCULA

Interrogação - ?

Exclamação - !

Pausa curta - ,

Pausa longa - .

Comentários descritivos do transcritor - ((minúscula))

Indicação de que a fala foi tomada ou interrompida em determinado ponto - [...]
} 
cenário plurilíngue e intercultural, partimos da perspectiva das línguas inseridas em seus contextos reais de uso; assim, questões relacionadas a representações e identidades acabaram por emergir na interação com os participantes da investigação e serão discutidas no presente artigo.

A partir da presente introdução, o artigo está estruturado da seguinte forma: primeiramente, apresentamos brevemente a formação social e histórica do contexto específico da pesquisa. Após, dedicamos uma seção para discutir o bi/plurilinguismo, as políticas linguísticas e outras abordagens teóricas às quais nos ancoramos. Em seguida, analisamos os dados, isto é, os excertos das entrevistas a partir dos quais foi possível refletir sobre questões de representação relativas às línguas que fazem parte da vida dos participantes da pesquisa. Por fim, tecemos as considerações finais, com o intuito de contribuir para o debate em torno dos cenários plurilíngues existentes no Brasil e sua relação com os processos de escolarização.

\section{O contexto da pesquisa}

Situamo-nos na região sul do Brasil, mais particularmente, no Vale do Itajaí, localizado no Estado de Santa Catarina. A história desse contexto se delineou por meio de diversos acontecimentos e desdobramentos que o constituíram enquanto cenário plurilíngue. A partir do início do século XIX, a região recebeu diversos imigrantes provenientes de países europeus. “A colonização [...] surgiu de uma lógica geopolítica de povoamento, articulada à ocupação de terras públicas consideradas 'vazias' - sem qualquer consideração pela população nativa, classificada como nômade e incivilizada" (SEYFERTH, 2002, p. 119).

Assim que os imigrantes de língua alemã aqui chegaram, após o massivo incentivo às políticas imigratórias no Brasil, principalmente entre os anos de 1824 e 1930, fundaram diversas escolas e formaram um sistema de ensino. Esse sistema era organizado e coordenado principalmente por lideranças das igrejas católicas e evangélicas, que manifestavam sua preocupação com a promoção de um projeto humano-religioso junto às crianças que eram alfabetizadas em língua alemã. Porém, as lideranças e a população logo perceberam a necessidade de também ensinarem a língua portuguesa para as futuras gerações (KREUTZ, 2003).

As dificuldades e polêmicas em torno do ensino bilíngue e da preocupação especial com a língua portuguesa se estenderam durante todo o período no qual essas escolas religiosas e comunitárias existiram. Um fator que se faz relevante nessa questão são as localidades 
isoladas para as quais, muitas vezes, os grupos de imigrantes eram enviados e que geravam a ausência de contato com a língua portuguesa, muitas vezes, por um longo período. Dessa forma, as comunidades acabavam se constituindo de maneira mais homogênea, formadas apenas por descendentes de imigrantes advindos de uma mesma região ou país da Europa (SEYFERTH, 2002), o que não significa que não houvesse diferenças dentro desses mesmos grupos.

No início do século $\mathrm{XX}$, o governo brasileiro iniciou uma série de ações para desmontar essa aparente homogeneidade que se formara em diversas zonas de imigração. $\mathrm{O}$ objetivo dessas medidas dizia respeito à formação de uma nação unificadamente brasileira, a partir de um ideal monocultural. Assim, duas campanhas de nacionalização do ensino foram instituídas, atingindo notadamente os grupos de imigrantes e seus descentes. Na primeira delas, a partir de 1911, no estado de Santa Catarina, foram fechadas diversas escolas com o argumento de que a língua portuguesa deveria imperar como única língua de instrução.

Posteriormente, entre os anos de 1937 e 1945, foi implantada a segunda campanha de nacionalização do ensino, em âmbito nacional, durante o regime do Estado Novo de Getúlio Vargas, que intensificou a repressão linguística aos grupos de imigrantes. Dessa vez, outras instituições ligadas à língua alemã, como a imprensa e os clubes de caça e tiro, além do sistema de ensino, também foram alvo de perseguição (FÁ́VERI, 2004; GAERTNER, 2004; MAILER, 2003; FRITZEN; EWALD, 2016).

Assim, historicamente, o cenário nacional e regional, foco da pesquisa ora relatada, foi palco de ações voltadas ao monolinguismo e ao apagamento das diferenças culturais. Depois desse período de silenciamento explícito das línguas de imigração, o país passou por diversas fases no que diz respeito à inclusão e/ou exclusão das diversidades. Na próxima seção, apresentaremos um recorte acerca dos diversos movimentos político-linguísticos que aconteceram nos últimos anos, além de concepções teóricas nas quais nos apoiamos.

\section{Bi/plurilinguismo, políticas linguísticas e outras ancoragens teóricas}

Atualmente, mais de 6.000 línguas são faladas em nosso planeta que é composto, oficialmente, por 191 países. Esse número expressa a realidade plurilíngue em que vivemos. De acordo com Maher (2013, p. 118), “o multilinguismo mundial é um estado de normalidade, enquanto que o monolinguismo é um absoluto estado de exceção". Dessa forma, lançamos nosso olhar ao contexto foco da pesquisa com um questionamento constante em relação ao imaginário criado, historicamente, sobre a correspondência entre uma nação e uma língua. 
O Brasil, país de grande extensão territorial e repleto de diversas culturas, também é plurilíngue (MAHER, 2013). Isso significa que, ao lado da língua portuguesa como língua oficial, coexistem diversas outras manifestações linguísticas e culturais que muitas vezes não são reconhecidas. A ideia de que no Brasil só se fala português não existe por acaso, pois, de acordo com Cavalcanti (1999, p. 32), “desde o princípio de sua história, o Brasil é marcado por situações de conflito e repressão linguística". Muitos foram os embates em torno das línguas enquanto manifestações culturais e identitárias dos povos. Esses processos de repressão geraram diversas consequências para as representações que se constroem em torno do aparente monolinguismo brasileiro.

O mito do monolinguismo é uma criação discursiva e homogeneizadora, que "é eficaz para apagar as minorias, isto é, as nações indígenas, as comunidades imigrantes e, por extensão, as maiorias tratadas como minorias" (CAVALCANTI, 1999, p. 2). Quando o que está em jogo são línguas de prestígio, como, por exemplo, a língua inglesa (que é o principal foco de ensino e aprendizagem em escolas de idiomas), há o reconhecimento do bilinguismo enquanto algo desejável e que deve ser buscado pelas pessoas; porém, quando se trata de línguas minoritarizadas, a situação é diferente, pois o reconhecimento passa por questões sociais mais amplas, de constituição das identidades e representações sobre as pessoas, seus grupos e as línguas que falam.

A partir desse pressuposto, voltamo-nos às políticas linguísticas passadas e atuais em relação às línguas minoritárias: de acordo com Altenhofen (2013), logo após a segunda campanha de nacionalização do ensino, o Estado brasileiro passou por um período de indiferença em relação às diversas línguas faladas no cenário nacional, no qual não se proibia explicitamente, mas também não se incentivava o uso e aprendizado. Após, nos anos 70, a educação escolar indígena conquistou avanços em termos de políticas linguísticas e educacionais, com a adoção de uma perspectiva bilíngue e intercultural. Já no início dos anos 2000, o uso da LIBRAS (Língua Brasileira de Sinais) foi regulamentado pela legislação.

Mais especificamente no cenário local, no município onde residem os participantes foco da pesquisa, no ano de 2002, professores da rede municipal de ensino se reuniram, com o apoio da Secretaria Municipal de Educação e do IPOL (Instituto de Investigação e Desenvolvimento em Política Linguística), e iniciaram um programa de política linguística para o município. Inserido nesse programa estava o Projeto "Escolas Bilíngues", que pretendia, em escolas multisseriadas da região rural, oferecer o ensino da língua portuguesa e alemã de maneira simultânea e igualitária (MAILER, 2003).

Atualmente, no contexto da pesquisa, estão presentes grupos que ainda fazem uso das 
línguas de imigração, mesmo após todos os processos de repressão sofridos historicamente (EWALD, 2014). Estudos realizados anteriormente apontam que muitos deles, inclusive, permanecem fazendo uso de sua língua de herança (FRITZEN, 2007; MAILER, 2003). A língua alemã, enquanto língua minoritária, ainda é aprendida em casa e continua sendo usada no ambiente familiar como língua de interação (vide FRITZEN, 2011; MAAS; FRITZEN, 2014). Na pesquisa, nosso olhar se voltou especialmente a esses grupos e às suas manifestações linguísticas e culturais que ainda se fazem presentes, especialmente em localidades rurais.

Quando utilizamos neste artigo o termo "língua minoritária", referimo-nos a toda e qualquer língua que, não sendo reconhecida perante a sociedade e principalmente em relação à língua oficial do território brasileiro, acaba por não desfrutar do mesmo prestígio social e político do português, enquanto língua oficial, e de outras línguas “de elite” presentes em nosso país (MAHER, 2007). Essa distinção parece-nos importante ao olharmos para as relações desiguais entre as diversas formas de linguagem que estão em constante contato e conflito no contexto local e nacional nos quais nos inserimos.

Nesse sentido, concebemos a língua falada pelos sujeitos bilíngues em língua alemã como minoritária não por ser inferior ou de menor importância em relação à língua portuguesa, mas por ocupar um lugar à margem no que diz respeito ao reconhecimento, incentivo e amparo dentro das políticas linguísticas oficiais. Da mesma forma, aqui também se inserem as demais línguas presentes no território brasileiro que não são reconhecidas como tais, nesse cenário de aparente monolinguismo da língua portuguesa, como as línguas indígenas, as línguas de matrizes africanas, as diversas variações da língua portuguesa e as línguas de sinais.

Assim, designamos nosso contexto de pesquisa como um cenário culturalmente e sociolinguisticamente complexo (CAVALCANTI, 2011), pois se caracteriza pela coexistência de diferentes línguas e culturas, marcado por diversas formas de interações, crenças e atitudes que não coexistem harmonicamente, mas que passam por representações e pela constituição de identidade dos sujeitos envolvidos.

Quanto às ancoragens teóricas, no processo de geração (MASON, 2002) e interpretação dos dados, pautamo-nos nos pressupostos teóricos e metodológicos da Análise Dialógica do Discurso (PAULA, 2013), que permite a interlocução com outras áreas do conhecimento, partindo da materialidade linguística como um dos aspectos para se compreender a realidade mais ampla na qual os participantes da pesquisa se inserem. Dessa forma, abordamos a linguagem tanto na situação imediata vivida pelos sujeitos, quanto em 
suas questões sociais, políticas, econômicas e ideológicas com as quais os dizeres se relacionam.

Ao abordarmos o bilinguismo, fenômeno tão presente no contexto investigado, baseamo-nos nos pressupostos da Linguística Aplicada (RAJAGOPALAN, 2013; CANAGARAJAH, 2013; CAVALCANTI, 2011; MAHER, 2007) enquanto um campo interdisciplinar caracterizado por sua natureza prática e política, no qual o pesquisador assume responsabilidades frente aos desdobramentos de suas pesquisas e reflexões:

[...] existem vários tipos de sujeitos bilíngues no mundo, porque o bilinguismo é um fenômeno multidimensional. Somente uma definição suficientemente ampla poderá abarcar todos os tipos existentes. E, talvez, esta fosse suficiente: o bilinguismo, uma condição humana muito comum, refere-se à capacidade de fazer uso de mais de uma língua. (MAHER, 2007, p. 79, grifos nossos).

Dessa forma, bilíngues são tanto aqueles que aprenderam as línguas de maneira formal, como aqueles que apenas as utilizam na modalidade oral e em interações mais informais. A partir dessa perspectiva aberta de bilinguismo enquanto "uma condição humana muito comum", que não busca restringir essa característica àquelas pessoas que fazem uso de algumas modalidades e práticas específicas (e valorizadas) das línguas, olhamos de maneira receptiva para as diversas manifestações linguísticas que acontecem em nossa sociedade.

No presente artigo, ao nos propormos discutir representações sobre as línguas alemã e portuguesa que emergem dos enunciados de diferentes gerações, partimos da concepção de representação defendida pelos Estudos Culturais (SILVA, 1999; HALL, 2006): enquanto construção, criada e recriada na inter-relação entre linguagem, sujeitos e suas interações. Nesse sentido, representação não é apenas uma reprodução transparente de algum referente dado a priori, mas um sentido construído, por meio das diferentes relações, a todo o momento, e por meio da linguagem. Interessa-nos, assim, compreender o papel da escola em relação a esses sentidos que os sujeitos constroem sobre as línguas que falam, pois essas representações não são criadas apenas individualmente por eles, mas nas relações que estabelecem com demais sujeitos e instituições das quais participam.

\section{“Olha o alemão ali, olha o colono ali! ”: desvelando sentidos sobre representações}

Iniciamos esta seção apresentando os sujeitos entrevistados para a pesquisa maior. Conforme mencionado anteriormente, dessas entrevistas, foram selecionados excertos relativos às representações sobre as línguas presentes no contexto do estudo. 


\begin{tabular}{|c|c|c|}
\hline \multicolumn{3}{|c|}{ Família Sperber } \\
\hline Nome & Nascimento & Membro da família \\
\hline Dona Isabel & 1956 & Avó paterna \\
\hline Seu Líder & 1950 & Avô paterno \\
\hline Maria & 1975 & Mãe \\
\hline Cláudio & 1974 & Pai \\
\hline Guilherme & 2009 & Filho \\
\hline
\end{tabular}

Fonte: acervo das pesquisadoras

Quadro 01 - Sujeitos da família participante da pesquisa ${ }^{5}$

A primeira geração da família Sperber é formada por D. Isabel e Seu Líder. Quando da realização das entrevistas (2014), Dona Isabel tinha 58 anos de idade e seu esposo, Seu Líder, 64. Ambos vivem, desde o início de seu matrimônio, em uma casa na localidade foco da pesquisa. Esse casal de avós passa por momentos diários de convivência com os filhos e netos, pois todos residem nas proximidades. Ambos estudaram até a então $4^{\mathrm{a}}$ série do primeiro grau (hoje, ensino fundamental), quando tiveram de interromper os estudos para poderem continuar a contribuir com o trabalho de agricultura familiar. Ela sempre exerceu a função de dona de casa e seu marido trabalhou como agricultor durante toda a sua vida.

Durante a entrevista, realizada na residência dos participantes, eles foram convidados a falar sobre o processo de aprendizagem da língua portuguesa, uma vez que nos interessava compreender a escolarização dos sujeitos. As respostas de ambos se direcionaram para além do que havíamos perguntado, pois eles falaram sobre consequências e atitudes posteriores aos momentos em que estiverem inseridos na escola, onde aprenderam a língua portuguesa:

Pesquisadora: E como foi aprender português?

Seu Líder: Foi... foi pesado. Mas a gente aprendeu mais ou menos.

Dona Isabel: MAS tem muita coisa que a gente não aprendeu. A gente fala muito errado o português. Às vezes a gente conversa com as pessoas e às vezes faltam palavras.

Ao afirmar que a gente fala muito errado o português, Dona Isabel manifesta uma apreciação valorativa com relação aos usos que faz da língua portuguesa, o que parece revelar sua baixa autoestima linguística (BAGNO, 2015), uma imagem negativa que ela reproduz em relação a si mesma e às línguas que fala, ao elevar o seu tom de voz e enfatizar MAS tem muita coisa que a gente não aprendeu. No caso desses dois sujeitos da primeira geração, essa atitude parece vir à tona no movimento de comparação entre seus desempenhos linguísticos em língua alemã, enquanto língua aprendida e utilizada até hoje no ambiente familiar, e a língua portuguesa, enquanto língua obrigatória e aprendida formalmente apenas em alguns

\footnotetext{
${ }^{5}$ A fim de preservar a identidade dos sujeitos participantes, todos os nomes usados neste artigo são pseudônimos.
} 
anos de frequência escolar. $O$ vínculo que os sujeitos têm com cada língua é bastante diferente: há questões afetivas, familiares e culturais envolvidas nessas relações e, assim, a capacidade e o desempenho em cada uma dessas línguas também serão diferentes, sem necessidade de hierarquização entre elas.

Dona Isabel, durante toda a entrevista, conversou em língua portuguesa, bem como em todos os outros momentos de diálogo com a pesquisadora, por telefone, anteriormente. Assim, a dissonância existente entre o fato de esses sujeitos conseguirem se comunicar em língua portuguesa, por um lado, e de afirmarem que aprenderam essa língua mais ou menos, por outro, sugere uma imagem negativa que esses sujeitos têm sobre seus próprios desempenhos linguísticos como um imaginário construído discursivamente. Esse sentimento em relação à língua portuguesa diz respeito a uma representação negativa que foi criada ao longo do tempo. Aqui também estabelecemos uma relação com o processo de escolarização vivenciado por esses sujeitos. Seu Líder, ao afirmar, foi pesado [o aprendizado do português] desvela os conflitos desse processo, que poderia ter contribuído para a construção de relações mais colaborativas entre a língua já falada por eles e aquela que deveria ser aprendida na instituição formal. Na escola, Dona Isabel e Seu Líder conheceram a língua portuguesa enquanto norma, de caráter obrigatório e distante de suas realidades enquanto descendentes de imigrantes que falavam exclusivamente a língua alemã em seus demais espaços de interação.

De acordo com Freire (2014, p. 26, grifos nossos), “a palavra instaura o mundo do homem. A palavra, como comportamento humano, significante do mundo, não designa apenas as coisas, transforma-as; não é só pensamento, é práxis". Nesse sentido, a partir de uma perspectiva de língua enquanto construção ininterrupta, a realidade linguística e cultural dos sujeitos é criada e recriada a todo o momento, a partir de suas representações sobre eles mesmos, sobre as línguas que falam e sobre o mundo no qual estão inseridos. Ao não se considerarem suficientemente proficientes em língua portuguesa, Seu Líder e Dona Isabel se colocam nessa posição de inferioridade e deixam de lado outros fatores que dizem respeito ao uso que fazem do português, como o fato de terem conversado conosco durante várias horas e de termos nos entendido em língua portuguesa durante todo o momento da entrevista.

Ainda com o olhar voltado à problematização sobre as diferentes representações criadas e reproduzidas sobre as línguas e, consequentemente, sobre os falantes dessas línguas, apresentamos os dizeres de Cláudio, membro da segunda geração da família Sperber, que trabalhou, durante seu período de infância, na agricultura, que era o meio de obtenção de renda de sua família. Ele estudou até a então $4^{\mathrm{a}}$ série do ensino fundamental e, então, parou de frequentar a escola para poder contribuir mais no trabalho familiar. Após, iniciou sua 
trajetória de trabalho formal em uma empresa da região quando tinha 14 anos de idade e continua, até hoje, a trabalhar nesse mesmo local.

Cláudio: Na nossa época o alemão era o alemão, era a língua que a gente falava aqui dentro só. Era a nossa língua só. Olha o alemão ali, olha o colono ali! [...] Até então nós era uns alemãozinho que trabalhava na roça, desde criança. Eu, minha mãe e meus irmãos sempre trabalhamos na roça.

A entrevista possibilitou a Cláudio colocar-se em uma posição exotópica em relação aos acontecimentos e a ele mesmo, e estabelecer uma relação com um tempo e espaço localizados no passado, nos quais a utilização e importância da língua alemã parecem restritas ao seu contexto familiar: era a nossa língua só. E, em oposição a essa língua que a gente falava aqui dentro só, existia a língua portuguesa enquanto manifestação linguística oficial que possuiria um valor mais alto em comparação à língua de herança utilizada cotidianamente por esse sujeito e sua família.

De acordo com Altenhofen (2013, p. 95), “[...] a discriminação que normalmente se associa às línguas minoritárias não é inerente à língua e à sua definição, mas reflete uma situação social vigente que demanda justamente de uma política e de um planejamento linguístico, para resolver conflitos e disparidades". Assim, nenhuma língua é considerada mais ou menos valiosa a priori, mas apenas a partir de critérios estabelecidos de forma externa a ela. Em interação com os dizeres de Cláudio, o qual afirma que na nossa época, nós era uns alemãozinho que trabalhava na roça, refletimos sobre a representação que existia sobre as populações descendentes de imigrantes, juntamente com desprestígio relacionado ao trabalho rural com a língua falada por esse grupo. Tanto língua quanto tipo de trabalho, aqui, apresentam-se enquanto caracterização de um determinado grupo, como marca identitária daqueles que exercem determinadas funções, falam determinada língua e, assim, representam determinado grupo.

Da mesma forma que a linguagem acontece como uma forma de interação, como diálogo entre diferentes sujeitos socialmente posicionados (BAKHTIN, 2009), as representações que os sujeitos têm sobre as línguas faladas por eles e, consequentemente, sobre eles mesmos, só será materializada a partir de uma construção conjunta, com a assimilação de pontos de vista externos que se ressignificam internamente no grupo. Assim, a percepção que Cláudio tem sobre a identidade de seu grupo (olha o alemão ali! Olha o colono ali!) se constrói na relação com outras identidades (HALL, 2006), diferentes, não alemãs e não residentes no campo. Essa caracterização de si não se dá a partir de si mesmo apenas, uma 
vez que sempre haverá um referente externo (BAKHTIN, 2009) no qual nos amparamos para valorar o mundo ao nosso redor.

Ampliando nosso olhar em relação às interações em língua alemã e portuguesa, apresentamos um excerto de entrevista no qual os sujeitos refletem sobre outros espaços e situações de aprendizagens linguísticas e culturais:

Seu Líder: eu vou te contar uma história. Eu trabalhava num prédio, isso era uma fábrica de plástico. Na fábrica que eu trabalhava, que fechou em 84, tinha só umas três pessoas que falavam alemão, o resto era italiano e polaco. Ali a gente aprendeu mais do que mesmo que na escola.

Dona Isabel: Hoje em dia tem outras palavras pra tudo, não é mais aquele português que nós aprendemos na nossa época. Porque tu não acompanha mais tudo. Hoje em dia ainda eu aprendo português com meus netinhos.

Seu Líder: Quando eu tava trabalhando LÁ embaixo, lá era três alemãos e os outros só italianos e polacos, misturados.

Dona Isabel: Essas pessoas falam mais português né, assim a gente aprendia mais português.

Ao afirmar que ali a gente aprendeu mais mesmo do que na escola, Seu Líder sinaliza o ambiente de trabalho enquanto uma esfera na qual o aprendizado da língua portuguesa acontecia na interação entre os sujeitos, a partir dos diversos usos e sentidos que iam sendo construídos, para muito além de uma imposição ou obrigação normativa. Enquanto a instituição escolar desconsiderava (e ainda desconsidera em muitos contextos) a língua de herança familiar, tornando obrigatório apenas o português como língua oficial, na esfera do trabalho essa língua oficial também era utilizada e aprendida, com diferentes sujeitos em situações reais, nas quais o seu uso se fazia necessário. O ambiente de trabalho parece que se pautava, talvez de maneira não planejada, em uma perspectiva intercultural e plurilíngue, apresentando-se enquanto espaço potencializador da interação entre sujeitos de diferentes culturas em situações de constante negociação e aprendizagem.

Podemos relacionar essa experiência vivenciada por Seu Líder ao que Calvet (2002, p. 146) denomina de gestão do plurilinguismo que acontece a partir das atitudes dos próprios falantes em relação às línguas: "refere-se ao modo como as pessoas, cotidianamente confrontadas com problemas da comunicação, os resolvem". Assim, a interação entre as diferentes línguas, na vida dos sujeitos, acontece enquanto prática, enquanto necessidade de adaptação às diferentes pessoas que convivem em um mesmo ambiente, em contraposição às medidas coercitivas que poderiam proibir ou tentar controlar o movimento dessas formas de manifestação cultural. 
De acordo com Altenhofen (2013, p. 103, grifos nossos), políticas linguísticas dizem respeito a:

[...] um campo de decisões das relações da sociedade com as línguas [...] não se restringe às decisões do Estado, mas sim engloba decisões de cidadãos e grupos ou entidades sociais que implicam uma motivação de direito e de dever, por se imporem como regra (prescritiva ou proscritiva), e não apenas como atitude linguística.

Dessa forma, a partir dos excertos das entrevistas com os membros das diferentes gerações que apresentamos até então, depreendemos a existência de um poder bastante frutífero de modificação e condução das práticas linguísticas pelos próprios sujeitos que são, ao mesmo tempo, alvo e agentes das políticas oficiais. Afinal, as políticas linguísticas são modificadas, gerenciadas e aprimoradas, todos os dias, nos contextos reais de interação (ALTENHOFEN, 2013) e, por mais que o controle pareça acontecer de maneira determinista, as pessoas também podem, localmente, agir em favor de mudanças. As relações de força serão desiguais, mas elas acontecerão tanto em espaços microestruturais quanto macroestruturais.

O dizer de Seu Líder, de que lá era três alemãos e os outros só italianos e polacos, misturados, sinaliza a língua como marca de identidade, que identifica seus lugares de origem e, principalmente, as práticas exercidas até hoje por eles. A busca pela unificação cultural e linguística, como fruto das sociedades modernas no processo de invenção das nações europeias, mostra aqui os seus reflexos. Tão ideologicamente forte esse projeto aconteceu que, até hoje, os sujeitos fazem uso dessa caracterização, aparentemente natural, para se referirem uns aos outros. A invenção das nações (BERENBLUM, 2004), aqui principalmente expressa pela utilização de uma língua, mostra sua força e poder de perpetuação ao longo dos anos.

A partir do que enunciou Dona Isabel, eu aprendo português hoje com meus netinhos, é possível refletir sobre o papel que têm a família e as novas gerações na conquista de espaço também para a língua portuguesa. Mais uma vez, nessa esfera extraescolar, a aprendizagem acontece de forma interativa, com diferentes sujeitos aprendendo por meio das práticas sociais, pois, de acordo com Dona Isabel, não são apenas os mais novos que aprendem com os mais velhos. Para esses sujeitos, as esferas familiar e profissional aparecem enquanto proporcionadoras de contato e aprendizagem com diferentes línguas e identidades.

Ainda levando em conta a inter-relação existente entre as diferentes gerações e as línguas presentes nesse contexto, trazemos para discussão um trecho da entrevista com Guilherme e sua mãe Maria. Ele é membro da terceira geração da família Sperber, tinha seis 
anos de idade quando da geração dos dados e passa todas as manhãs da semana na casa dos avós, devido ao horário de trabalho dos pais. No período da tarde, frequenta a escola da comunidade, a mesma instituição desde que iniciou seu período de escolarização, na educação infantil:

Pesquisadora: que língua que tu aprendeu em casa, primeiro, com teu pai e tua mãe?

Guilherme: $e u$...

Maria: primeiro. eh::

Guilherme: alemão

Pesquisadora: e na escola?

Guilherme: daí...

Maria: daí foi português né

Guilherme: sim. Português

Pesquisadora: e na escola tem outras crianças que falam alemão?

Guilherme: Tem.

Pesquisadora: E tu fala em alemão com elas?

Guilherme: Às vezes ((risos))

Pesquisadora: Quando?

Guilherme: Só na aula de alemão.

(...)

Maria: Antes quando ele não ia para a escola, ele só sabia alemão, aí quando nós colocamos ele com quatro anos na escola, ai eles pediram assim para começar a falar português em casa, porque se não seria difícil para ele se enturmar com a turma. E foi questão de 3, 4 semanas, ele aprendeu tudo português e deixou o alemão mais de lado que o português. Ele mesmo diz sozinho que acha mais fácil o português. Pesquisadora: tu acha mais fácil o português?

Guilherme: agora que eu aprendi, sim.

Primeiramente, o contexto linguístico e social de Guilherme e sua família pode ser apresentado a partir do primeiro diálogo entre ele e a pesquisadora. A língua alemã ainda se faz muito presente em suas relações familiares e comunitárias: tanto em casa, quanto no bairro e nas atividades da igreja, por exemplo. Antes de começar a frequentar a escola, a rotina de Guilherme era pautada no uso da língua alemã, principalmente com seus avós, com os quais ele convive diariamente enquanto os pais estão no trabalho. Porém, diferentemente de seus pais, o contato do menino com a língua portuguesa foi acontecendo de forma mais sutil e progressiva, pois, atualmente, a língua portuguesa está presente em todos os programas de televisão, por exemplo, aos quais a criança sempre teve acesso dentro e fora de casa.

O enunciado de Maria, apresentado na sequência, faz uma ponte com o diálogo da entrevistadora com Guilherme anteriormente. Os dizeres da mãe, aqui, podem ser analisados enquanto uma representação, bastante pessoal e afetiva, repleta de sentimentos e valores, acerca das mudanças que aconteceram em relação às práticas de seu filho após sua entrada na escola. Parece que, antes da escola, a mãe conseguia preservar com mais facilidade a 
utilização da língua de herança nas interações de sua família. Por mais que seus dizeres possam ser um tanto quanto especulativos, ao levarmos em conta sua relação afetiva com essa língua, também podemos depreender mudanças que aconteceram a partir da escolarização do membro da terceira geração dessa família.

Maria, ao relatar que quando nós colocamos ele com quatro anos na escola, aí eles pediram assim para começar a falar português em casa, porque se não seria difícil para ele se enturmar com a turma, remete-nos ao que Cavalcanti (2011) afirma sobre a ainda afirmação do monolinguismo em nosso contexto social e cultural brasileiro. A escola, ao requisitar que as práticas familiares sejam modificadas para a melhor adaptação da criança, age contra a promoção de uma pedadogia multicultural e plurilíngue. Pois, assim, não há incentivo pela manutenção e continuidade da língua de herança já presente no ambiente familiar, mas a ideia de substituição pela língua dominante e oficial.

Na afirmação de Guilherme acerca de sua preferência atual pela utilização da língua portuguesa (agora que eu aprendi, sim), atentamo-nos à expressão agora, utilizada enquanto demarcação temporal que nos leva à reflexão acerca das mudanças pelas quais as relações entre ele e sua língua de herança vêm passando: acostumado a utilizar a língua alemã em suas relações familiares, Guilherme se depara com novas práticas, nas quais a língua portuguesa era requisitada, ao entrar na escola. De acordo com Cox e Assis-Peterson (2011, p. 32), “é através do uso da língua que nos tornamos membros de uma comunidade de idéias e práticas". Nesse sentido, inferimos que a atual preferência desse sujeito da terceira geração pela língua portuguesa está relacionada com sua construção identitária, em novos espaços e situações de interação das quais ele pode participar devido ao fato de poder se comunicar em língua portuguesa.

Assim, chegamos ao final da discussão dos dados que selecionamos para este artigo com o reconhecimento de que a construção das identidades dos sujeitos são motivadas por aspectos como as línguas que falam, os espaços que frequentam e o trabalho que realizam. A construção da identidade é, portanto, "construção discursiva permanentemente (re)feita a depender da natureza das relações sociais que se estabelecem" (MAHER, 2010, p. 37) entre os grupos sociais.

\section{Considerações finais}

Com o propósito de discutirmos representações sobre as línguas alemã e portuguesa que emergem dos enunciados de diferentes gerações, podemos inferir que tanto a língua 
alemã quanto a portuguesa possuem papéis, funções e valores distintos na vida dos sujeitos, e vão se modificando a partir dos lugares sociais que esses sujeitos ocupam, com o passar do tempo (e das gerações). As representações acerca de cada língua são construções que estão em constante relação com questões econômicas e de poder de cada momento sócio-histórico específico. O português, para as duas primeiras gerações, foi a língua da escola, obrigatória, uma língua distante das práticas dos sujeitos até então. Esse período curto de escolarização marcou esses sujeitos de forma negativa com relação ao aprendizado do português. Já a língua alemã, praticada oralmente e nunca estudada no ambiente escolar, continua sendo parte da vida dos participantes da pesquisa como herança familiar.

A valorização ou estigmatização das línguas muda de acordo com cada momento histórico, com os discursos e consequentes representações que se constroem sobre as línguas e os sujeitos que as falam. Assim, as representações sobre as línguas não são estanques e imutáveis, mas relacionadas ao contexto específico no qual estão inseridos seus falantes. Nesse sentido, a expressão valorativa representada pelo membro da terceira geração também é construída nos contextos em que ele está inserido, especialmente a partir da sua escolarização, num espaço em que a língua alemã não foi acolhida e deveria ser evitada. A escola, não raro, acaba tendo um papel fundamental sobre as representações que se constroem acerca das línguas de imigração e sobre sua manutenção ou não na comunidade.

Num momento atual propício para o debate em torno da diversidade cultural e do plurilinguismo, não podemos deixar de enfatizar a necessidade de reconhecimento e valorização dos contextos bi/plurilíngues ainda existentes em tantas localidades brasileiras. Para que isso ocorra, é preciso discutir e efetivar políticas de educação linguística em favor de uma pedagogia culturalmente sensível (ERICKSON, 1996) aos saberes locais, aos conhecimentos vividos, com vistas ao fortalecimento das línguas minoritárias e ao direito ao seu aprendizado nas escolas públicas brasileiras.

\section{REFERÊNCIAS}

ALTENHOFEN, C. V. Bases para uma política linguística das línguas minoritárias no Brasil. In: NICOLAIDES, C; SILVA, K. A.; TILIO, R.; ROCHA, C. H. (Orgs.) Política e políticas linguísticas. Campinas: Pontes Editores, 2013, p. 93-116.

BAGNO, M. Preconceito linguístico: o que é, como se faz. São Paulo: Loyola, 2015. BAKHTIN, M. (V. N. Volochínov). Marxismo e filosofia da linguagem. 16. ed. São Paulo: Hucitec, 2009. 
BERENBLUM, A. A invenção da palavra oficial: identidade, língua nacional e escola em tempos de globalização. Belo Horizonte: Autêntica, 2004.

CALVET, L. J. Sociolinguística: uma introdução crítica. Tradução de Marcos Marcionilo. São Paulo: Parábola, 2002.

CANAGARAJAH, A. S. Navigating language politics: a story of critical praxis. In:

NICOLAIDES, C. et al. (Orgs.) Política e políticas linguísticas. São Paulo: Editora Pontes, 2013. p. 43-61.

CAVALCANTI, M. C. Estudos sobre educação bilíngue e escolarização em contextos de minorias lingüísticas no Brasil. DELTA, São Paulo, v. 15, número especial, p. 385-418, 1999. CAVALCANTI, M. C. Um olhar metateórico e metametodológico em pesquisa em Linguística Aplicada: implicações éticas e políticas. In: MOITA LOPES, L. P. (Org.) Por uma Linguística Aplicada INdisciplinar. (Org.) São Paulo: Parábola Editorial, 2006. p. 233252.

CAVALCANTI, M. C. Multilinguismo, transculturalismo e o (re)conhecimento de contextos minoritários, minoritarizados e invisibilizados. In: MAGALHÃES, M. C. C.; FIDALGO, S. S. (Orgs.) Questões de método e de linguagem na formação docente. Campinas: Mercado de Letras, 2011, p. 171-185.

COX, M. I. P.; ASSIS-PETERSON, A. A. La enseñanza de inglés en los colegios públicos de Brasil: un retrato en blanco y negro. Revista Educación y Pedagogía, Antioquia, v. 20, n.51, p. 123-139, maio/ago. 2008.

ERICKSON, F. Transformation and school success: the politics and cultures of education achievement. In: JACOB, E.; JORDAN, C. (Orgs.) Minority education: anthropological perspectives. Norwood, New Jersey: Ablex Publishing Corporation, 1996. p. 153-181. EWALD, L. "Essa mancha ficou!": memórias sobre práticas de letramento em cenário de imigração alemã. Dissertação de Mestrado. Universidade Regional de Blumenau (FURB). 2014.

FAVERI, M. de. Memórias de uma (outra) Guerra: cotidiano e medo durante a Segunda Guerra em Santa Catarina. Florianópolis: UFSC; Itajaí: Univali, 2004.

FREIRE, P. Pedagogia do oprimido. 56. ed. Rio de Janeiro: Paz e Terra, 2014.

FRITZEN, M. P. "Ich kann mein Name mit letra junta und letra solta schreiben": bilingüismo e letramento em uma escola rural localizada em zona de imigração alemã no Sul do Brasil. Tese (Doutorado em Linguística Aplicada). Universidade Estadual de Campinas, 2007. FRITZEN, M. P. Reflexões sobre práticas de letramento em contexto escolar de língua minoritária. DELTA, São Paulo, v. 27, n.1, p. 63-76, 2011.

FRITZEN, M. P. "Ia na escola alemã e de um dia pro outro fechou. E nós não sabíamos falar o português": refletindo sobre as políticas linguísticas em contexto de língua minoritária.

Linguagem \& Ensino, Pelotas, v.15, n.1, p. 113-138, jan./jul. 2012.

FRITZEN, M. P.; EWALD, L. Reflexões sobre políticas de educação linguística em contexto plurilíngue. Educação \& Realidade, Porto Alegre, v. 41, n. 2, p. 491-512, abr./jun. 2016. GAERTNER, R. A matemática escolar em Blumenau (SC) no período de 1889 a 1968: da Neue Deutsche Schule à Fundação Universidade Regional de Blumenau. Rio Claro: UNESP, 2004. 248f. Tese (Doutorados em Educação Matemática). Instituto de Geociências e Ciências Exatas, Universidade Estadual de São Paulo, Rio Claro, 2004.

HALL, S. A identidade cultural na pós-modernidade. Tradução: Tomaz Tadeu da Silva, Guacira Lopes Louro. 11. ed. Rio de Janeiro: DP \& A, 2006.

KREUTZ, L. Língua de referência na escola teuto-brasileira: as tensões entre o uso do alemão e do português. In: CUNHA, J. L.; GÄRTNER, A. (Orgs.) Imigração alemã no Rio Grande do Sul: história, linguagem, educação. Santa Maria, RS: EUFSM, 2003, p. 133-157. 
MAAS, M. R.; FRITZEN, M. P. A língua alemã em antiga zona de imigração no vale do Itajaí (SC): um estudo em duas comunidades. Calidoscópio, São Leopoldo, v. 12, n. 2, p. 143152, mai/ago 2014.

MAHER, T. M. Do casulo ao movimento: a suspensão das certezas na educação bilíngüe e intercultural. In: CAVALCANTI, M.; BORTONI-RICARDO, S. M. (Orgs.)

Transculturalidade, linguagem e educação. Campinas, SP: Mercado de Letras, 2007. p. 6794.

MAHER, T. M. Ecos de resistência: políticas linguísticas e línguas minoritárias no Brasil. In: NICOLAIDES, C. et al. (Orgs.) Política e Políticas Linguísticas. Campinas: Pontes Editores, 2013. p. 117-134.

MAHER, T. M. Políticas linguísticas e políticas de identidade: currículo e representações de professores indígenas na Amazônia ocidental brasileira. Currículo sem Fronteiras, v.10, n.1, p. 33-48, jan/jun 2010.

MAILER, V. C. O. O alemão em Blumenau: uma questão de identidade e cidadania. Florianópolis: UFSC, 2003. 95f. Dissertação (Mestrado). Centro de Comunicação e Expressão, Programa de Pós-Graduação em Linguística, Universidade Federal de Santa Catarina, Florianópolis, 2003.

MASON, J. Qualitative researching. 2. ed. SAGE publications, 2002.

PAULA, L. de. Círculo de Bakhtin: uma Análise Dialógica de Discurso. Rev. Est. Ling., Belo Horizonte, v. 21, n. 1, p. 239-258, jan./jun. 2013.

PRETI, D. (Org.) O discurso oral culto. 2. ed. São Paulo: Humanitas Publicações FFLCH/USP, 1999.

RAJAGOPALAN, K. Política linguística: do que é que se trata, afinal. In: NICOLAIDES, C.; et al. (Orgs.) Política e Políticas Linguísticas. Campinas: Pontes Editores, 2013.p. 19-42.

SEYFERTH, G. Colonização, imigração e a questão racial no Brasil. Revista USP, São Paulo, n. 53, p. 117-149, mar./maio 2002.

SILVA, T. T. Documentos de identidade: uma introdução às teorias do currículo. Belo Horizonte: Autêntica, 1999. 